\title{
Detection of Eye Movements of ALS Patients
}

\author{
Eli Kolberg* \\ Faculty of Engineering, Bar-Ilan University, Israel \\ *Corresponding author: Eli Kolberg, Faculty of Engineering, Bar-Ilan University, Israel
}

\begin{tabular}{|c|c|}
\hline ARTICLE INFO & ABSTRACT \\
\hline Received: 业 June 24, 2019 & \multirow{2}{*}{$\begin{array}{l}\text { Citation: Eli Kolberg. Detection of Eye Movements of ALS Patients. Biomed J Sci \& Tech } \\
\text { Res 19(2)-2019. BJSTR. MS.ID.003285. }\end{array}$} \\
\hline Published: 紫 July 02, 2019 & \\
\hline
\end{tabular}

\section{Introduction}

ALS is one of the most common neuromuscular diseases worldwide, and people of all races and ethnic backgrounds are affected. ALS most commonly strikes people between 40 and 60 years of age, but younger and older people also can develop the disease. For severe disabled people, communication abilities are highly limited. In this paper, we describe a method that makes the communication possible with low cost equipment and help the patient to activate a GUI such that certain eye movements move a cursor on a pre-designed screen and each time the cursor moves, it say the word that it pointed to. If the patient decides to choose this wort, they blink with their eyes and the word is heard again and is written to a file. The session terminates when the patient blinks more than pre-defined number of times in a row.

Methods to detect eye-movement and gaze tracking involve either infrared illumination or high- resolution camera. Some works relates to use of low-resolution camera or using laser. Some method uses deep learning algorithms. The main difficulty with those methods is that severe patients close their eyes and using a camera or laser will not be a proper solution. Addition obstacle is the fact that all methods assume relatively clean signals with no additional muscle movement or the noise that is produced from various machines attached to the patient. The method we will use is based on the Electro-Ocular Gram (EOG) signal for determining the position of the pupil of the eye.

\section{Objectives}

a. A system that will allow identification of eye movements (left or right or blink) of ALS patients b. A GUI that will allow for easy use of the system for communication with ALS patients

\section{Analysis of the Original EOG Signal}

EOG signal is usually accompanied with noise stem from environment signals and biological signals like EEG and EMG. The literature, describe a two stages process for producing the signal. First stage includes amplifying the signal by a differential amplifier and the second stage includes filtering the signal by low pass filter with cutoff frequency of $38 \mathrm{~Hz}$. The first stage differential amplifier inputs are the signals received from right and left eyes. It should reject the common signal for the two inputs (noise) and amplify the difference between the two signals. The purpose of the following stage, which is low pass filter, is to filter out the environmental noise (Figures $1 \& 2$ ).

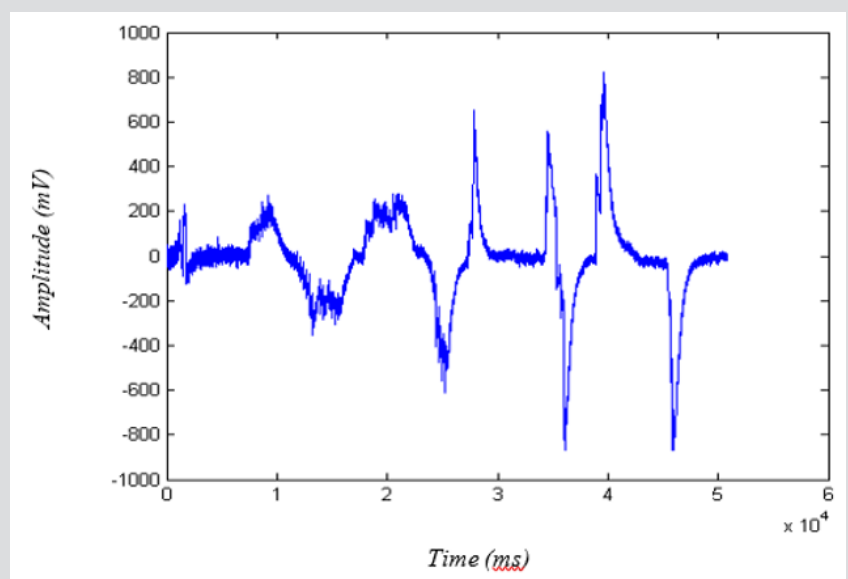

Figure 1: Time (ms) Clean EOG signal. 


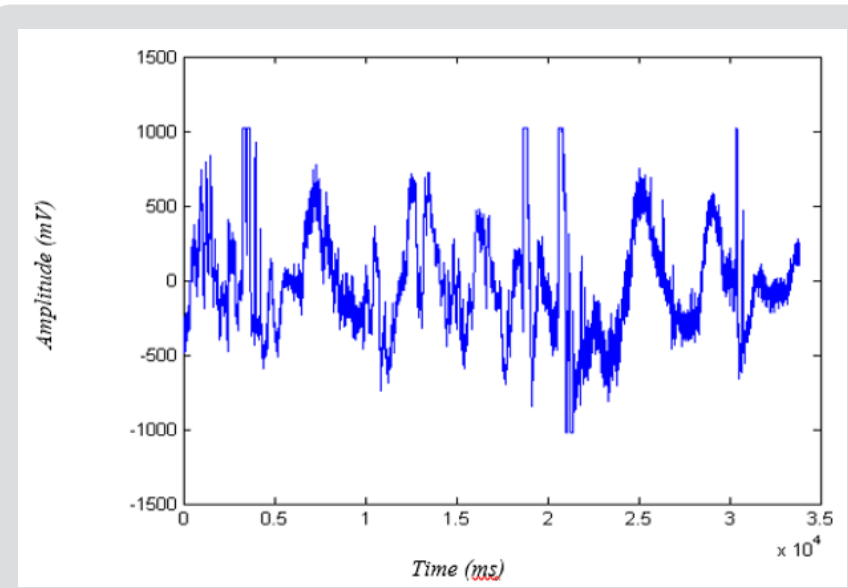

Figure 2: Time (ms) EOG signal with noise.

When we tested the system, we discovered that while the signal is reasonable when no other muscle besides the eyes move, it is noisy and unpredictable when any other muscle is active, like with laughter, moving the head, etc. In addition, we discovered that in contrast to the description that the voltage is a function of the position of the eye, that when the eye move to a new position, the voltage becomes zero few milliseconds after the eye settles in a new position. From what we studied, there is a need for better solution for the system.

Most of the time, the values in the clean and noisy signals have the same scope. Thus, the band pass filter does not allow for separation between a clean signal and a noise. We will analyze the signals and will have to find a way to filter the signals such that it will be available for further manipulation. The research should come out with a solution to overcome these noises such that only one type of signal will be present, in the frequency domain.

\section{Method}

EOG signal is generated by dipoles located in the eyes with the cornea having relatively positive potential with respect to the retina as a result of the movement of eyeballs within the conductive environment of the skull. There is a substantial electrical noise that comes with the EOG signal due to among others, physiological signals like EEG (stem from brain activity), and EMG (stem from muscles activity). The EOG based system for aid to disabled people will consists of five parts: Amplification and filtering of the EOG signal, sampling the outcome signal, digital processing of the signal, transmitting the signal to a computer.

\section{Software and User Interface}

The system will analyze horizontal eye movements to right and left sides. The EOG signals received by the software will be coded to commands with three symbols for each command. The symbols will be "right", "left", and "center". The overall algorithm will include:

1. Open the general display,

2. Calibrate the system with specific user (only for the first time),

3. Display detailed instructions and a menu for manipulator commands,

4. Receive the user movement succession, including canceling specific movement and problems identification,

5. Approve/deny of the incoming movement succession, 6 . Send the proper command to the computer.

\section{User GUI}

The GUI can be a computer GUI that will include a matrix of rows and columns. Each row will include pre-defined words. When the patient moves their eyes, it will pronounce the word. If the patient chose to select the word they will blink, and the word will be entered to a sentence. Other type of communication can be operating a robotic manipulator.

\section{Testing}

We will test the system in hospital after receiving approval of Helsinki committee.

\section{References}

1. Hansen DW, Pece AE C (2005) Eye tracking in the wild. Comput Vis Image Underst 98(1): 155-181.

2. Kawato S, Tetsutani N (2004) Detection and tracking of eyes for gazecamera control. Image Vis Comput 22(12): 1031-1038.

3. Magee JJ, Betke M, Gips J, Scott MR, Waber BN (2008) A human-computer interface using symmetry between eyes to detect gaze direction. IEEE Trans On Sys Man Cybernetics 38(6): 1248-1261.

4. Samadi MR H, Neil Cooke (2014) EEG signal processing for eye tracking. Proc. $22^{\text {nd }}$ European Signal Processing Conference (EUSIPCO), pp. 20302034.

5. Mayaud L, Congedo M, Van Laghenhove A, Orlikowski D, Figère M (2013) A comparison of recording modalities of p300 Event Related Potentials (erp) for Brain-Computer Interface (bci) paradigm. Neurophysiol Clin 43(4): 217-227. 


\section{ISSN: 2574-1241}

DOI: 10.26717/BJSTR.2019.19.003285

Eli Kolberg. Biomed J Sci \& Tech Res

(c) (i) This work is licensed under Creative

Submission Link: https://biomedres.us/submit-manuscript.php

$\begin{array}{ll}\text { BIOMEDICAL } & \text { Assets of Publishing with us } \\ \text { RESEARCHES } & \text { - Global archiving of articles } \\ \text { - Immediate, unrestricted online access } \\ \text { - Rigorous Peer Review Process }\end{array}$

